\title{
Data Exploration on Overall Suicides Cases Registered Across India
}

\author{
K. Sai Teja ${ }^{1}$, S. Pravalika ${ }^{2}$, G. Varshitha ${ }^{3}$, Syed Muzamil Basha ${ }^{4}$, N. Ch. Sriman \\ Narayana Iyengar ${ }^{5}$ and Ronnie D. Caytiles ${ }^{6}$ \\ 1,2,3,5 Sreenidhi Institute of Science and Technology, Yamnampet, Ghatkesar, \\ Hyderabad, Telangana 501301 \\ ${ }^{4}$ Sri venkateswara college of engineering and technology, Chittoor, India. \\ ${ }^{6}$ Multimedia Engineering Department, Hannam University, Daejeon, Korea \\ srimannarayanach@sreenidhi.edu.in
}

\begin{abstract}
The prevalence of suicides registered among students and farmers show a discrepancy across countries and socio demographic populations. Whereas in India, in 2012, over 2200 students committed suicide, due to failure in exams. The other side, the farmers, ending up their life, as there is no other option of survival, i.e., Last final cry for help. It is commonly know that the agriculture is the backbone of India. But, many are unaware of pledge of the Indian farmer. Maharashtra a state in India constitutes for half of the farmer suicides in India. The state and central government of India should take necessary steps in stigmatizing illness The experiments carried out in our research deals with the dataset having 236583 observations and seven variables form year 2001-2012 describing out the suicide cases registered in India. The main focus, in our research is to address the risk factor in committing suicides among students and farmers in India. The findings in our research shows that, the Impact of committing is more in the Age group of 0-14 and 15-29.
\end{abstract}

Keywords: prevalence, suicides, stigmatizing, India

\section{Introduction}

According to the survey conducted by NDTV on 2013, It was declared that for every hour there are 15 suicides getting registered across India. In fact, more than 371 suicides every day, the reason behind all this suicides are instability in thinking, lack of motivation. Among all the suicide cases, 5.5\% of all suicide victims are students, on the other side farmers. Medical care claims that "person who attempts suicide shall be presumed to be suffering from mental illness at that time". In India, addressing this issue, a Mental Health care Bill got introduced in 2013 towards decriminalizing suicides. As per the records collected form 2001-2012, mostly students and farmers are vulnerable to suicides. Students committed suicide, due to failure in exams. The other side, the farmers. It is commonly know that the agriculture is the backbone of India. But, many are unaware of pledge of the Indian farmer. Maharashtra a state in India constitutes for half of the farmer suicides in India [14]. The government has been battling farmer suicides over 15 years. The problems being faced by the farmers are of grave importance. Vidarbha is a village in Maharashtra, where dams are constructed for irrigation. But, the outlet have not been started. This is the fundamental problem for the former as they are dependent on rain for their crops to grow. The BJP government as lunched a 15,000 crore scheme called "Jalyukta Shivaar Yojana" aims to make Maharashtra a drought-free

Received (December 19, 2017), Review Result (March 22, 2018), Accepted (March 27, 2018) 
state by 2019. While government is attempting to help, they are not even close to meeting the needs of the farmers. The life of the farmer is hard, working 12 hours a day, with limited resources and no guarantee of a yield due to the in consistent water supply. Adding to this the cost of production for cotton farming has increased with the introduction of genetically modified Bt cotton. However, this is the only crop whose rate is determined by the world market. This suicides as there is no proper training in this field. The state and central government of India should take necessary steps in stigmatizing illness. In the way to provide justification for the above statement made, we are conducting experiment on suicide dataset. The description of the dataset consider in our experiments are as follows. It contains 236583 observations and seven variables. The complete summary is provided in the Table 1.

Table 1. Description of the Suicide Dataset in India from 2001-2012

\begin{tabular}{|c|c|c|c|c|}
\hline State & Year & Type & Age_Group & Total \\
\hline $\begin{array}{l}\text { Karnataka : } \\
6792\end{array}$ & Min. :2001 & $\begin{array}{l}\text { Others (Please } \\
\text { Specify) } \\
: 7263\end{array}$ & $0-100+: 10920$ & Min. : 0.00 \\
\hline $\begin{array}{l}\text { Madhya } \\
\text { Pradesh: } 6792\end{array}$ & $\begin{array}{l}\text { 1st } \\
\text { Qu.:2004 }\end{array}$ & $\begin{array}{ll}\text { By Coming } \\
\text { Under Running } \\
\text { Vehicles/Trains: } \\
4200\end{array}$ & 0-14:45027 & 1st Qu.: 0.00 \\
\hline $\begin{array}{l}\text { Maharashtra } \\
: 6792\end{array}$ & $\begin{array}{l}\text { Median } \\
: 2007\end{array}$ & $\begin{array}{l}\text { By Consuming } \\
\text { Insecticides } \\
: 4200\end{array}$ & $15-29: 45223$ & Median : 0.00 \\
\hline $\begin{array}{l}\text { Andhra } \\
\text { Pradesh: } 6791\end{array}$ & $\begin{array}{l}\text { Mean } \\
: 2007\end{array}$ & $\begin{array}{l}\text { By Consuming } \\
\text { Other Poison } \\
: 4200\end{array}$ & $30-44: 45193$ & Mean : 30.64 \\
\hline $\begin{array}{l}\text { Odisha } \\
6791\end{array}$ & $\begin{array}{l}\text { 3rd } \\
\text { Qu.:2010 }\end{array}$ & $\begin{array}{l}\text { By Drowning } \\
: 4200\end{array}$ & $45-59: 45146$ & 3rd Qu.: 6.00 \\
\hline $\begin{array}{l}\text { Rajasthan : } \\
6791\end{array}$ & Max. :2012 & $\begin{array}{l}\text { By Fire-Arms } \\
: 4200\end{array}$ & $60+: 45074$ & Max. :8756.00 \\
\hline $\begin{array}{l}\text { (Other) } \\
: 195834\end{array}$ & $\mathrm{Na}$ & $\begin{array}{l}\text { (Other) } \\
: 208320\end{array}$ & $\mathrm{Na}$ & $\mathrm{Na}$ \\
\hline
\end{tabular}

\section{Literature Review}

In [1] the author used weighted fuzzy logic to assign weights in training the data to extract sentiments from the labeled tweets and achieved good F-score. where as in [2] the author made a detailed comparison on predictive models and perform analysis on Time series dataset. In [3] the author perform analysis on PIMA diabetes dataset and predicted the levels of diabetes based on insulin feature. where as in [4] the author used gradient ascent algorithm in finding out the exact weights of the terms used in determining the sentiment of tweet and used Boosting approach to improve the accuracy of linear classifier. In [5], the author provide a novel way of performing prediction on Breast cancer dataset, compared the performance of three different feature selection algorithm and proved that genetic algorithm is giving best result in selecting the best feature among all the available feature. SVM algorithms gives the best result in predicting the level of certainty in breast cancer. In [6], the author made an attempt to develop an recommender system, helping in searching the item, that might out found by themselves, In which precision and recall measures are used in measuring the performance of proposed model. In [7], the author made an research in solving the problem in Diabetic Retinopathy. In which, the author proposed a Model, which can capable of calculating the weights, that 
gives severity level of the patient's eye by using weighted Fuzzy C-means algorithm. In [8], the author proposed a build a model for airlines, that can performs sentiment analysis on customer feedback and achieved Vital accuracy. In [9], the authors aims to addresses the risk factors in completed suicides, In which, history of family, psychopathology and recent life events are analyzed as significant risk factors for completed suicide in India. In [10], the author finds that the temperature during India's main agricultural growing season has a strong positive effect on annual farmer suicide rates. In [11], the author suggests that Impatient suicides (IPS) needs early diagnosis and tolerable treatment of psychiatric disorders can prevent IPS to a great extent. In [12], the author identified that the environmental and psychological factors, are self-report measures helps in monitoring the behavior of a person.

\section{Methodology}

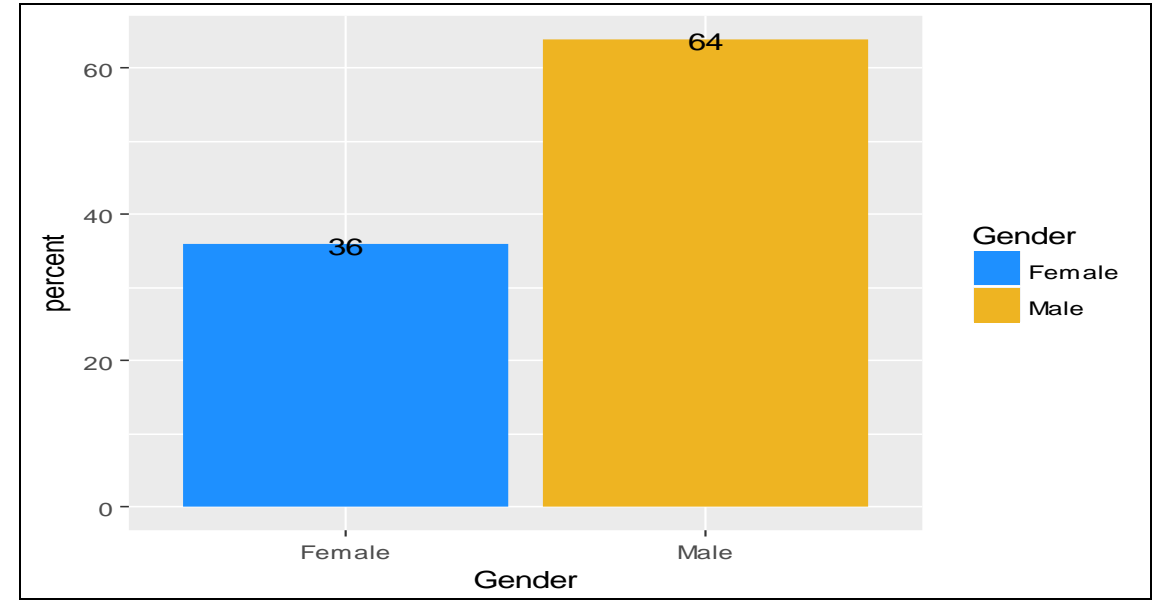

Figure 1. Percentage of Gender

From Figure 1, we can understand that, percentage of suicide is $64 \%$ in male, whereas in female, it is $36 \%$. It indicates that, Male gender have more depression levels compared to female gender. The next step is to find the age at which the male committed to suicide. The plot is as shown in Figure 2.

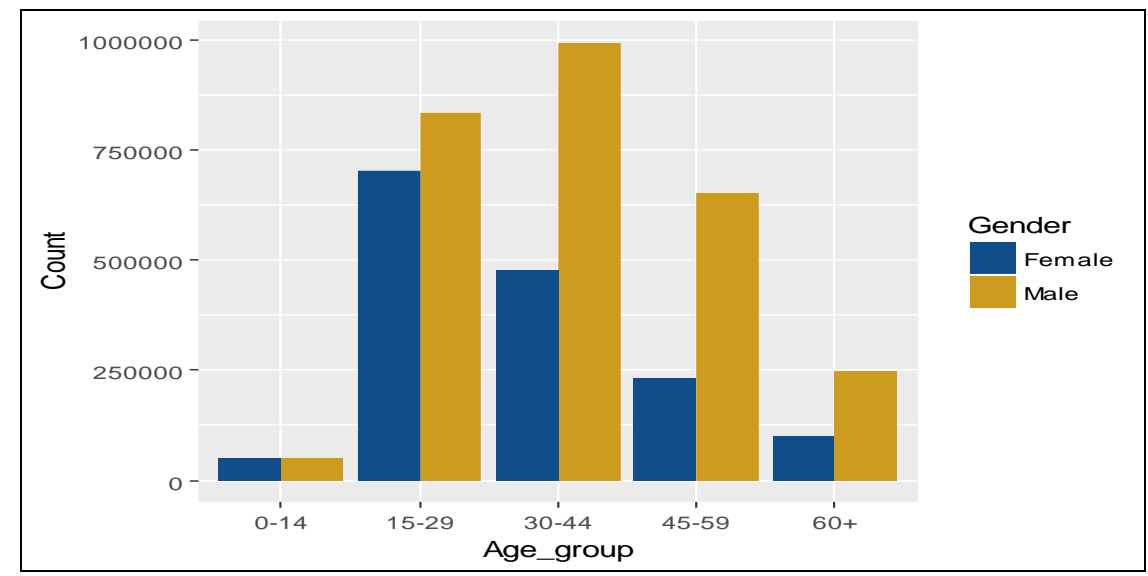

Figure 2. Age Group with Count (Male Vs Female)

From Figure 2 one can interpret that at 15-29 age group the female count in committing suicide is more, whereas at the age group of 30-44 male commit for 
suicide, that to after marriage. The total count at age group 15-29 is as shown in Figure 3.

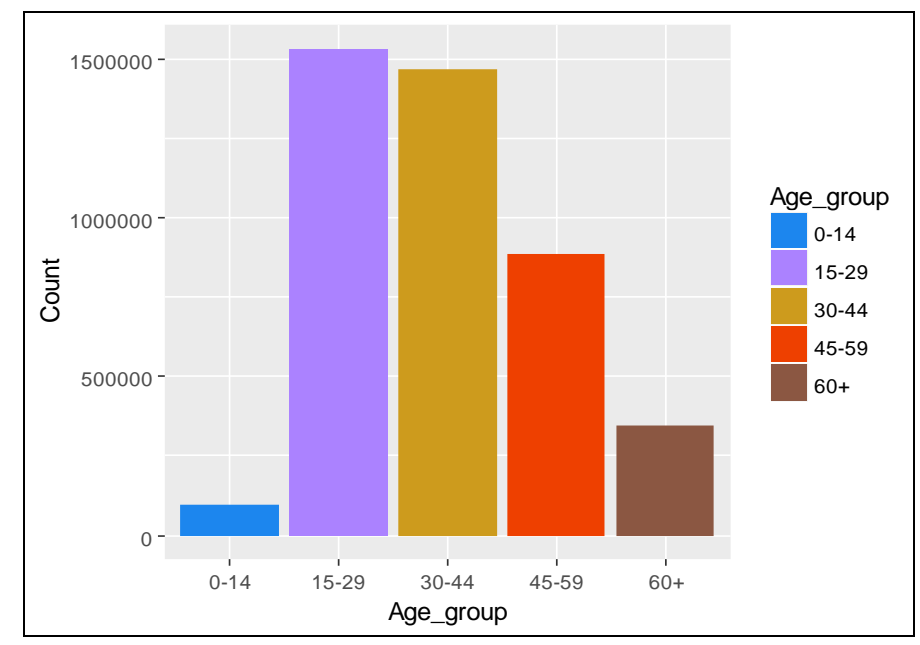

Figure 3. Age Group with Count (Total)

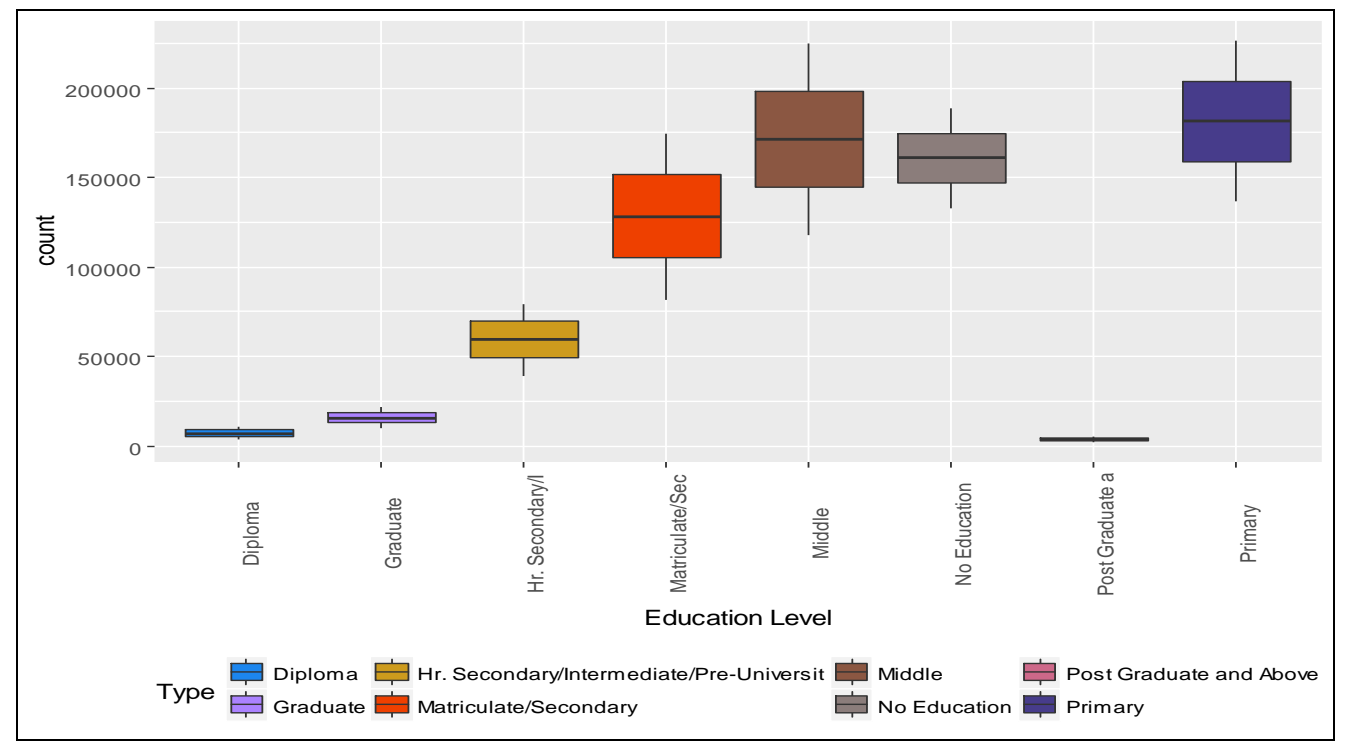

Figure 4. Educational Background of People

Next is to focus on the Education background of the people(Male and Female) of age group 15-29. From Figure 4 it is very clear that most of them have stopped their education with primary schooling, as their economical social status of parents are low. It is surprising to analyze from the obtained plot, that person with post graduation have very less chances of committing suicide. The count of Male and female in education background is plotted in Figure 5 as there is a need in finding out the problem with respect to gender. It makes everyone clear, that female education rate is low at all the levels of education. Thereby the state and central government of India should effectively promote the scheme like, "Beti padaw Beti Bachaw", inorder to increase the rate of women education at all levels of education. By this, the governments can make all the female to get prepared to face all the life challenges with proper mentoring [15]. Therefore, giving a proper education to their children's also depends on the social status of any family. Now, let us have a lot at it. From the Figure 6, one can easily interpret that, Married women with no 
educational background are heavily influenced to take such crucial decision in giving up their hope. Female with only primary education married at the age of 15 20 have much more changes in committing suicides. The parents of such females, should understand that, children of them are not going to be ready to get married at the age group of 15-20, without higher level of education.

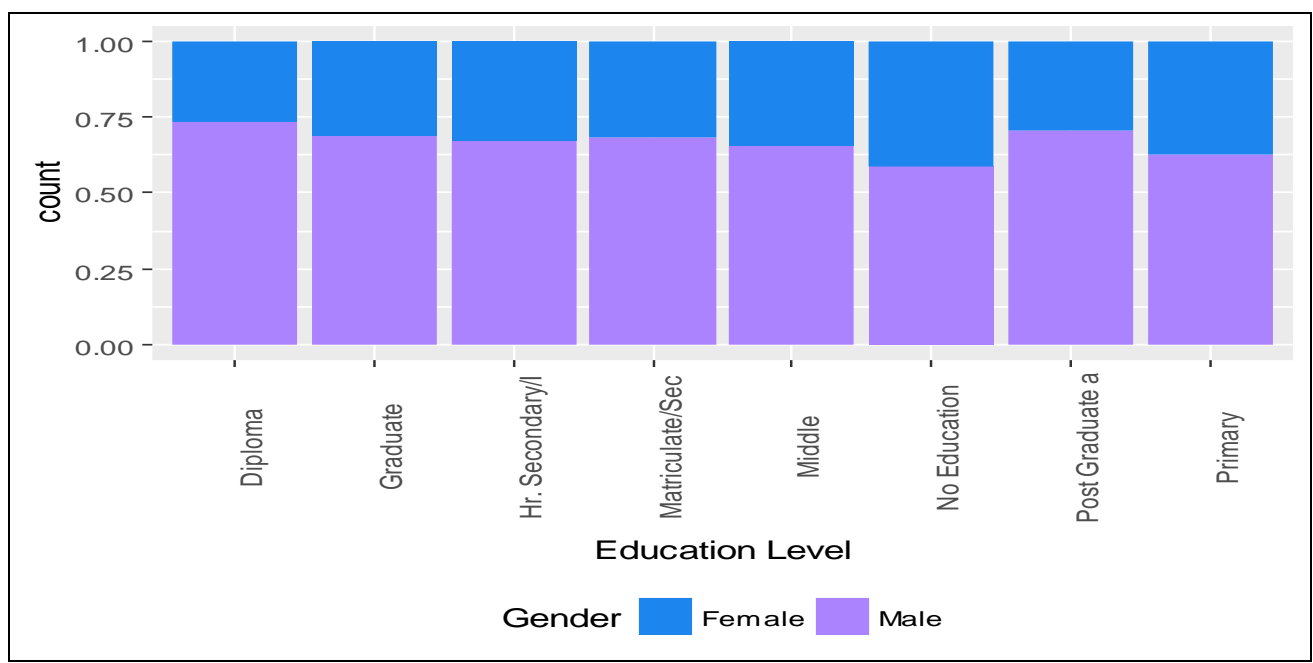

Figure 5. Educational Level Based on Gender

As they couldn't handle the responsibilities of New family members, as they are expected to be. Now let as have an understanding on the professional background of the female parents. As shown in the Figure 7. House wife without graduation, and getting married at the age group of 17-26, due to their parents social background. The next is, Female as student at graduation level is facing more challenges, parents treating them as friends makes them to feel better at home with full freedom. The next attribute to be given importance is victims professional profile, as in figure 8 . The top two based on the professional profile is, one is the house wife and the other is the farmer. House wife with only primary education and getting married at the age group of 15-26, due to their parents social status are mostly effected with depression and committing suicides.

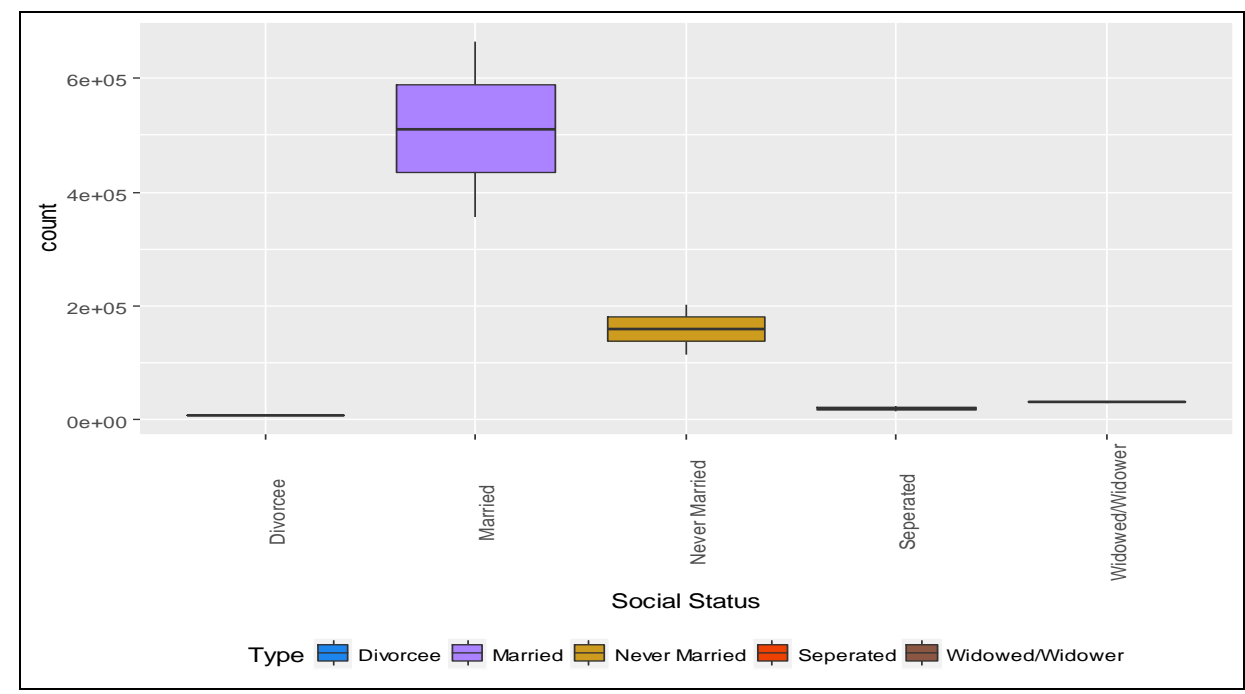

Figure 6. Social Status of Suicidal Victims 
And the next is the farmer, as the natural calamities, not getting continuous power supply and other are the reasons. The state and Indian government should look after this problems and provide effective schemes in providing proper mentoring in understanding the present challenges, prepare them to get ready to face new challenges by improving the decision making skills. The decision taken during depression may results in hurting them self by searching for easy method to commit suicide. on the other side Men, who mostly leads the family (Indian Conditions) have more chances to feel lonely and depressed with all the commitments made and thick much about the feature on which he don't have any control.

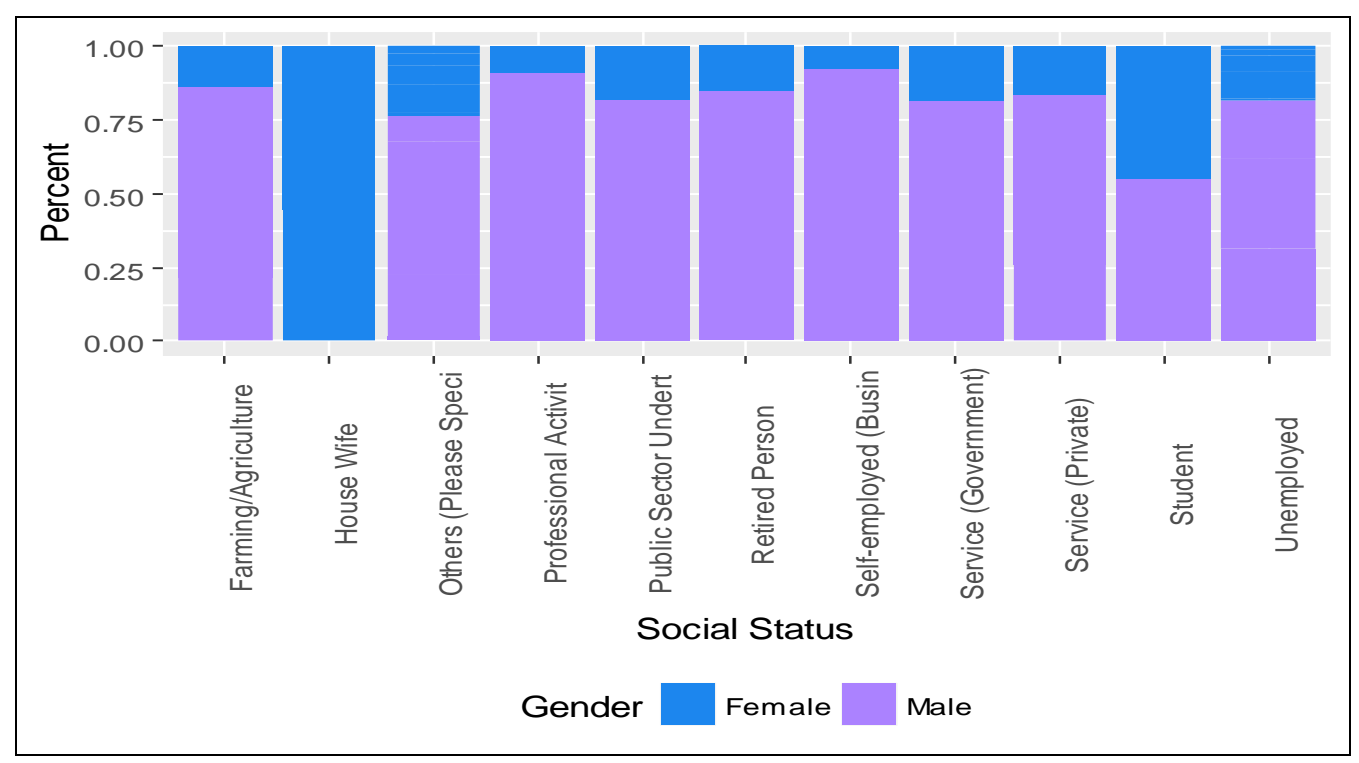

Figure 7. Social Status of Suicidal Victims Parents

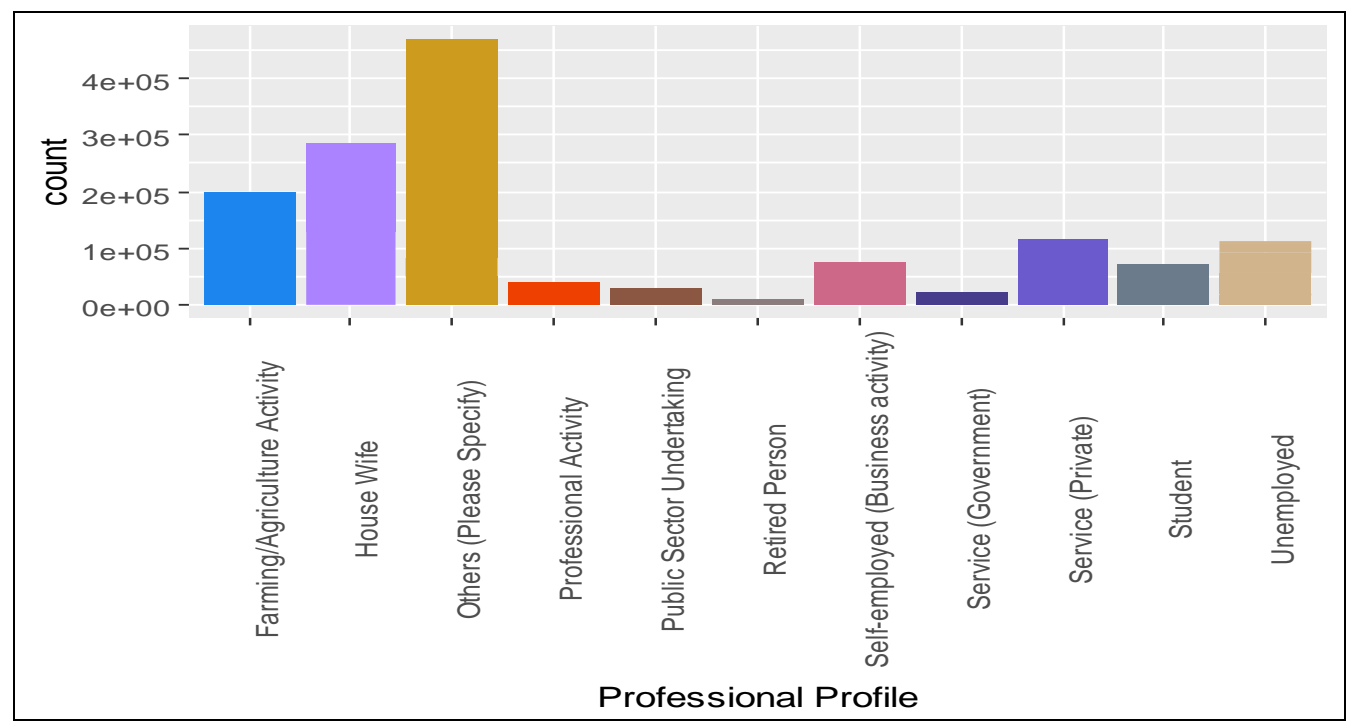

Figure 8. Professional Profile of Victim

From the Figure 9, it is easily understand that mostly man prefer to commit suicide by hanging, which is mostly accessible to him. The Next, is the farmer committing suicide by consuming insecticides, after deciding that which is of no more use after losing his/her cultivation. 


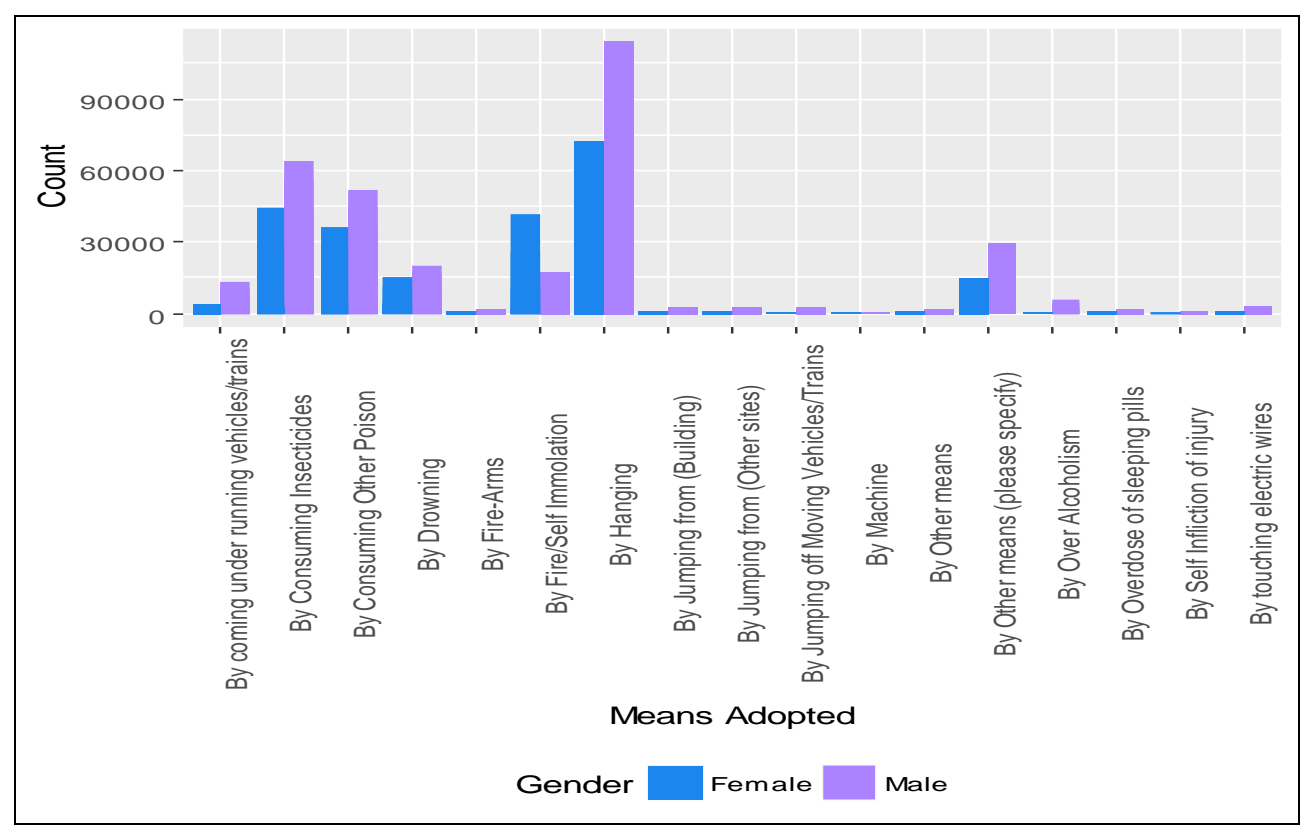

Figure 9. Means of Methods Adopted to Commit Suicide

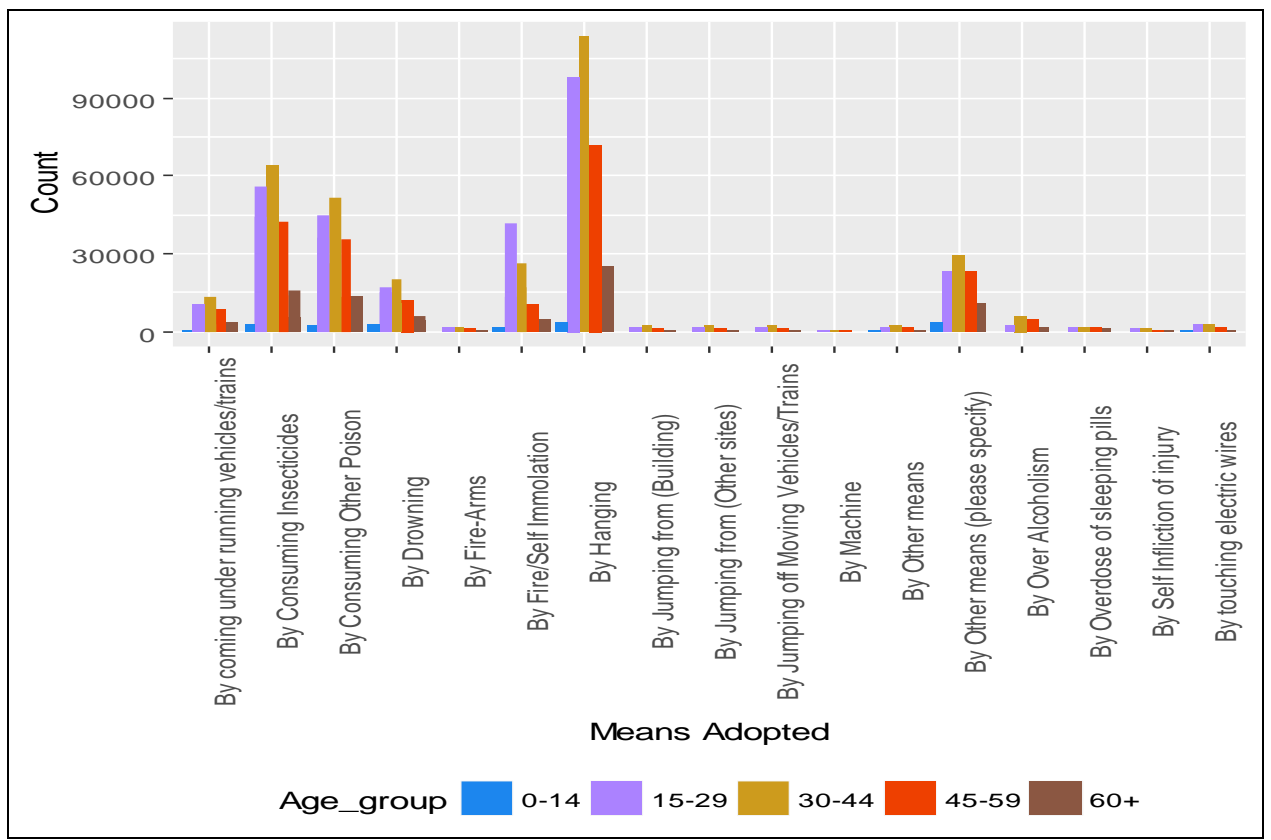

Figure 10. Means of Methods Adopted to Commit Suicide based on Age Group

From Figure 10, One can easily understand that at the age of 30-44 men after marriage is adopting the hanging method to commit suicide after feeling lonely. Our attempt is to find the other reasons, apart from family commitments. The answer is yes, the Figure 11 clearly makes us to understand that main cause to commit suicide by men at age group 30-44 is because Bankruptcy, love affairs impotency, cancellation of marriage and failure in examination (mostly in female). 


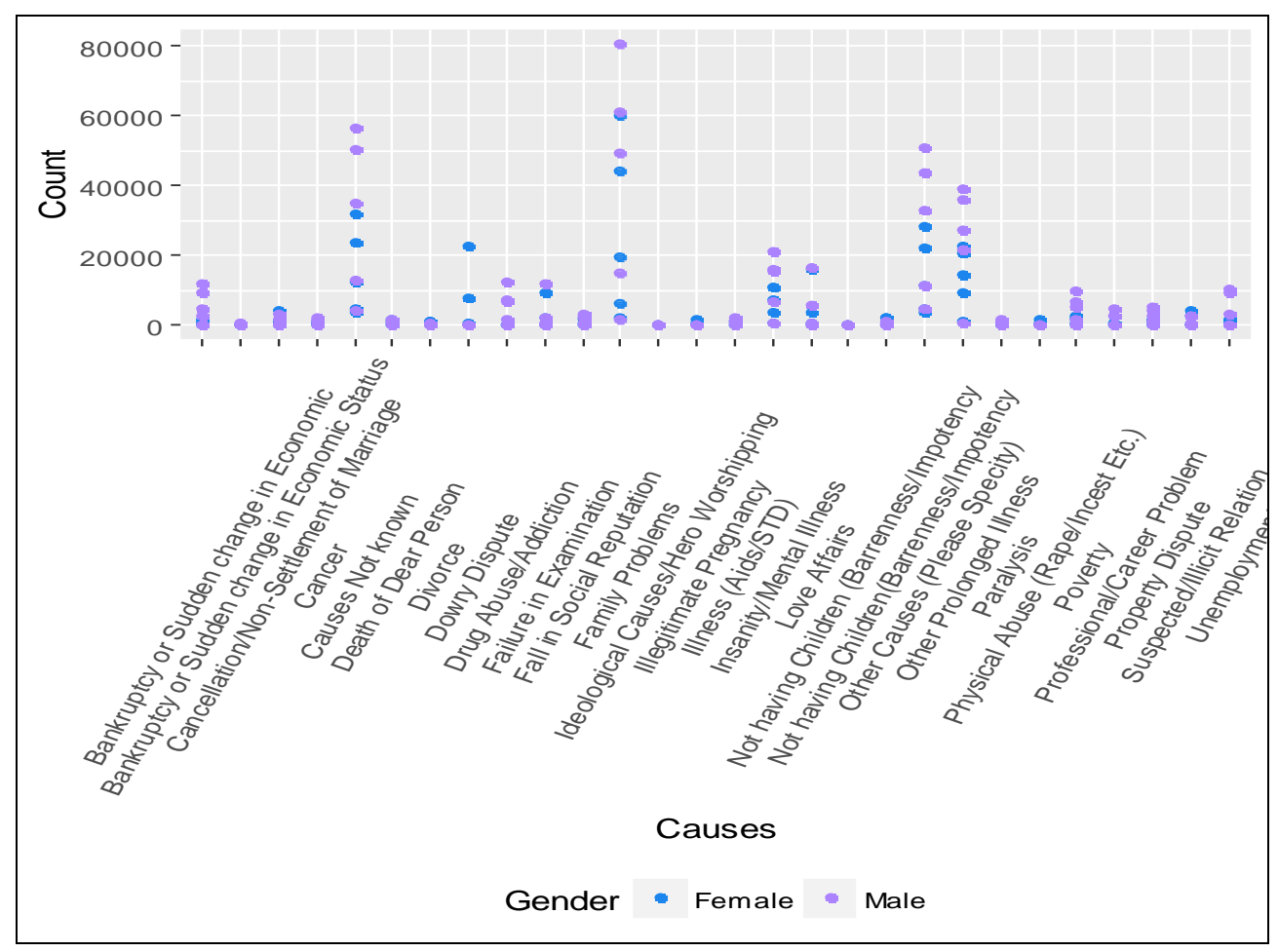

Figure 11. Causes for Committing Suicides at Age Group of 30-44

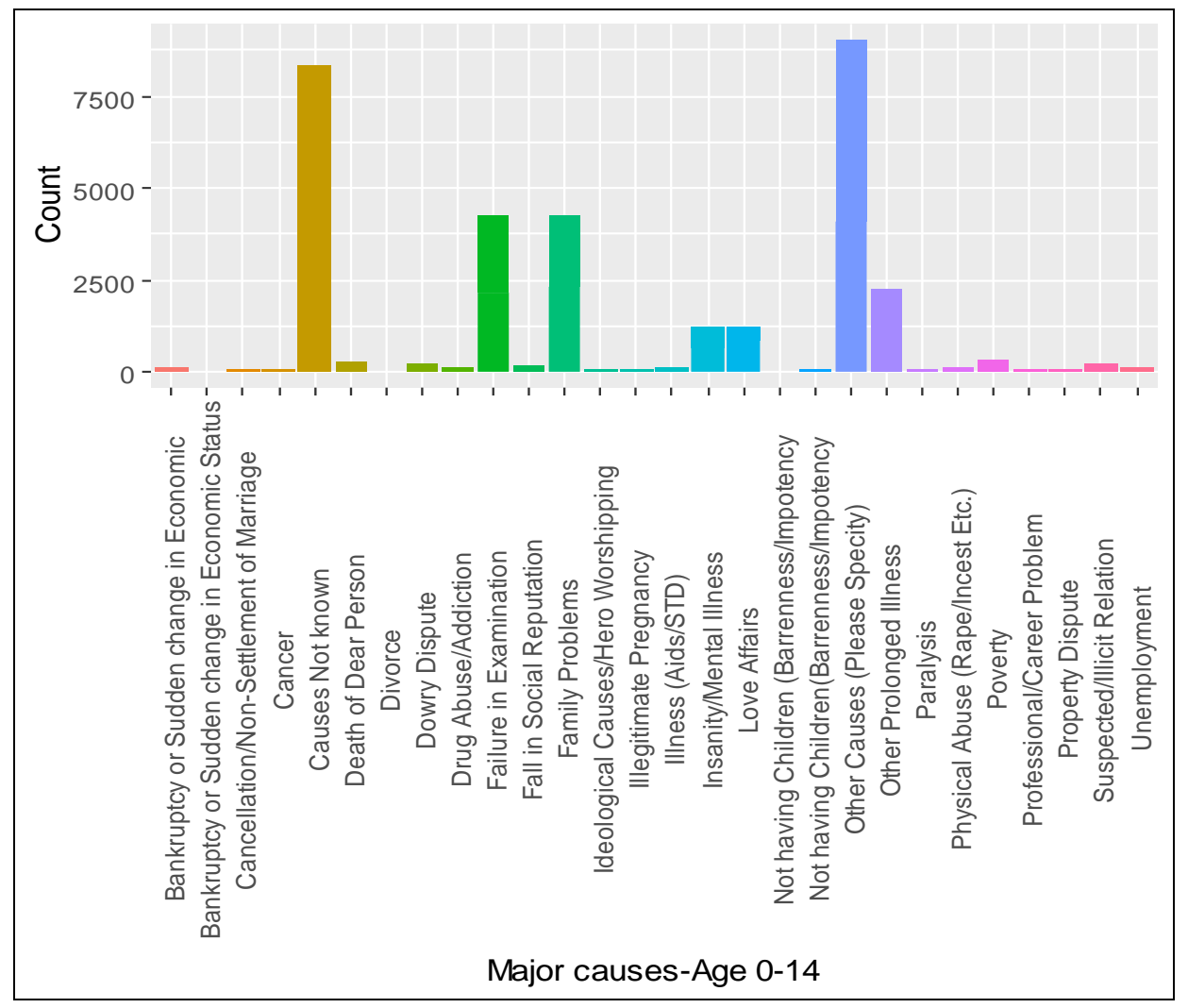

Figure 12. Major Causes for Committing Suicides at Age Group of 0-14 


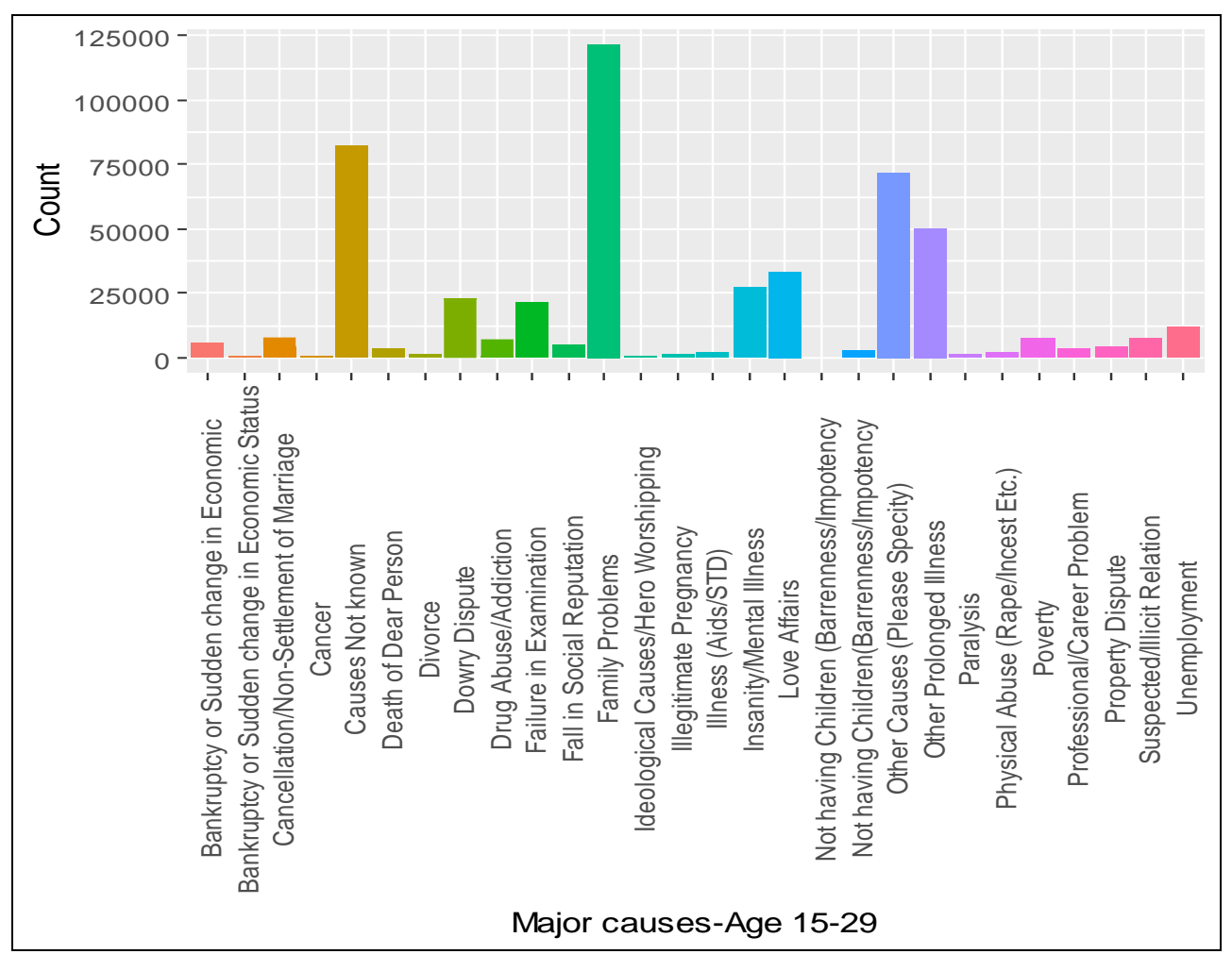

Figure 13. Major Causes for Committing Suicides at Age Group of 15-29

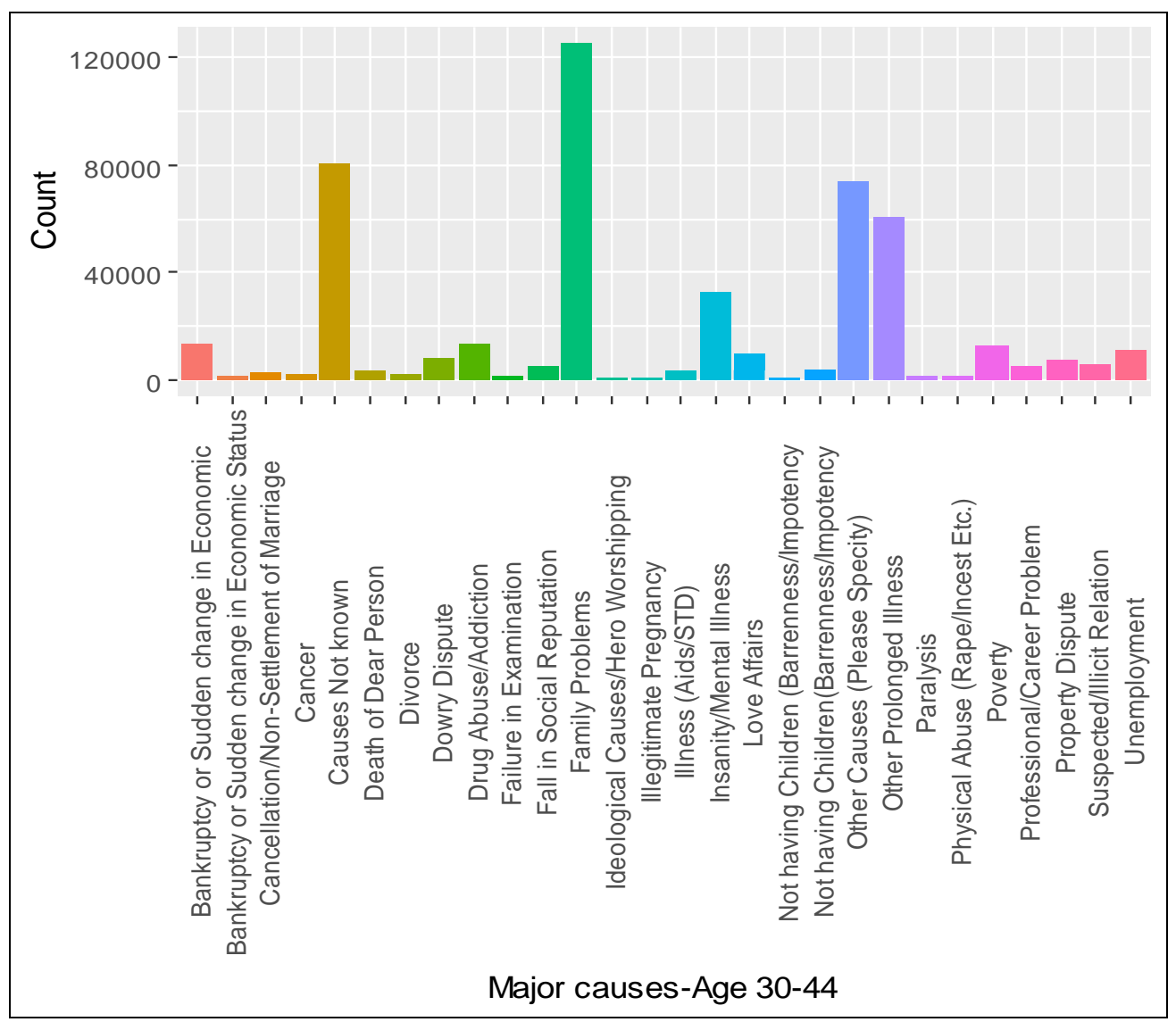

Figure 14. Major Causes for Committing Suicides at Age Group of 30-44 


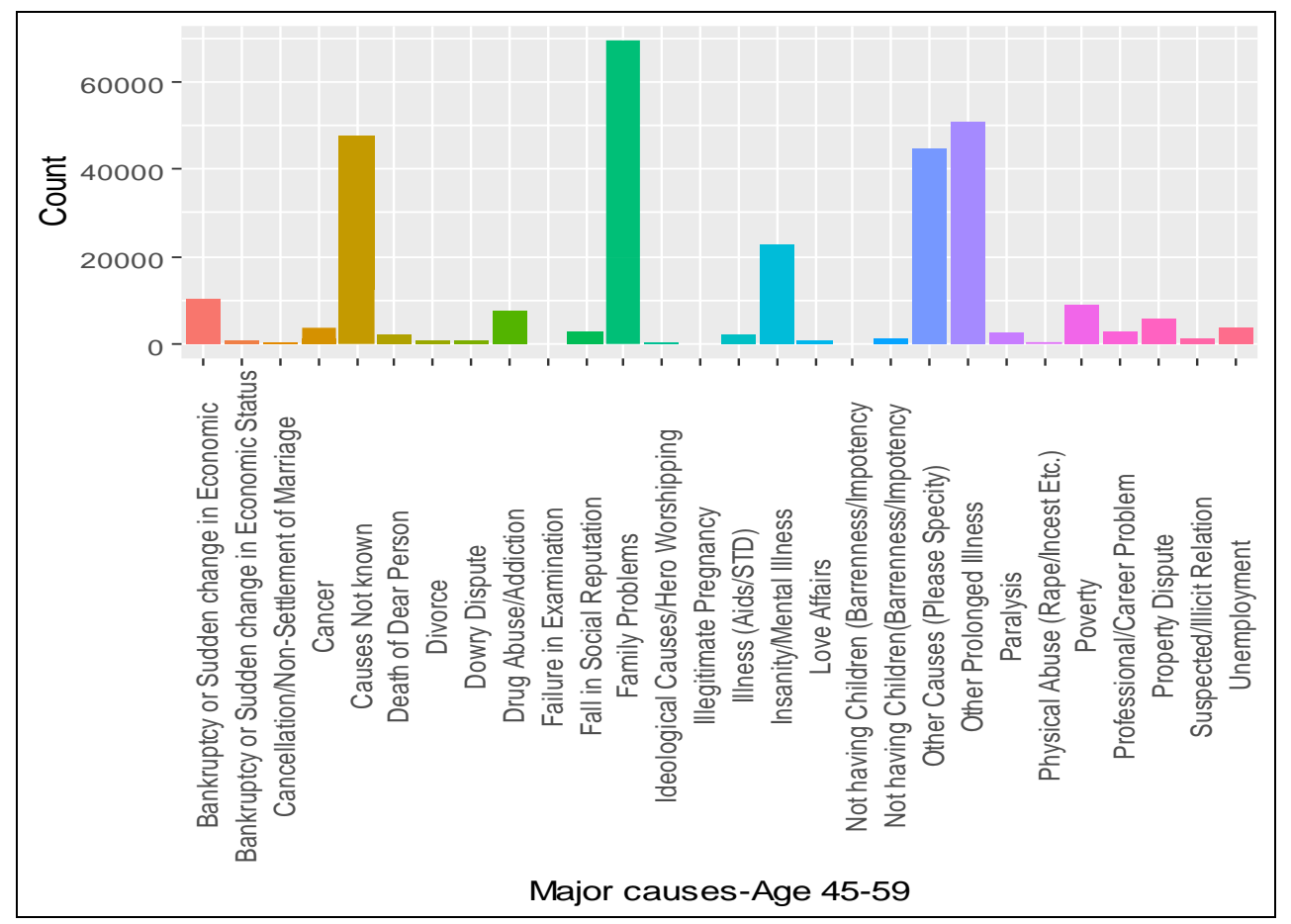

Figure 15. Major Causes for Committing Suicides at Age Group of 45-59

Now, let us have a closer look at the age group and the causes for committing suicide and the result of which is plotted in Figures 12 (0-14), 13 (15-29), 14 (3044), 15 (45-59), 16 (60-70). From all the above figure with respect to age group most of the suicides are because family problems [16].

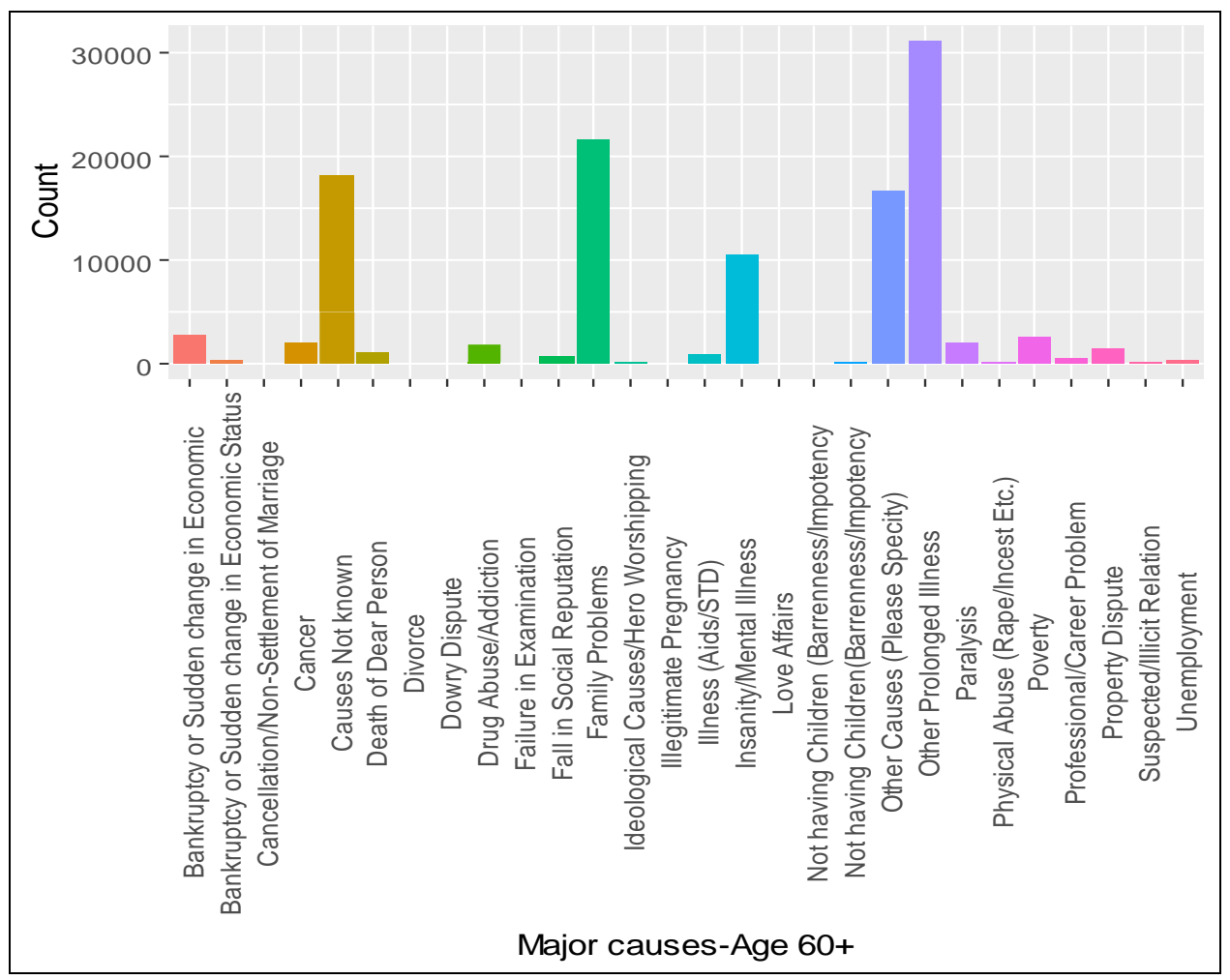

Figure 16. Major Causes for Committing Suicides at Age Group of 60-70 


\section{Results}

In [13], the author made an attempt to understanding the representations of neuron with in death-related and suicide-related concepts. And measures the performance of classifier in determining the state of participant. In Figure 22, state wise and year wise total number of suicides registered are plotted. In Figure 23, year wise from 2001-2012 total number of suicides based on different age group is plotted for better understanding. In Figure 17 the year wise plot (2001-2012) and causes for committing suicides are plotted. In which most of the suicides occur due to family problems and it is surprising to notice from 2006 it is gradually increasing and by 2012 it has reached to 35000 cases as per the dataset considered. In Figure 18 total number of suicide cases registered from 2001-2012 based on different age group is plotted. In Figure 19, state wise total number of suicide cases registered are plotted. In which, Maharashtra, West Bengal, Andhra Pradesh and Tamil Nadu are top among the list.

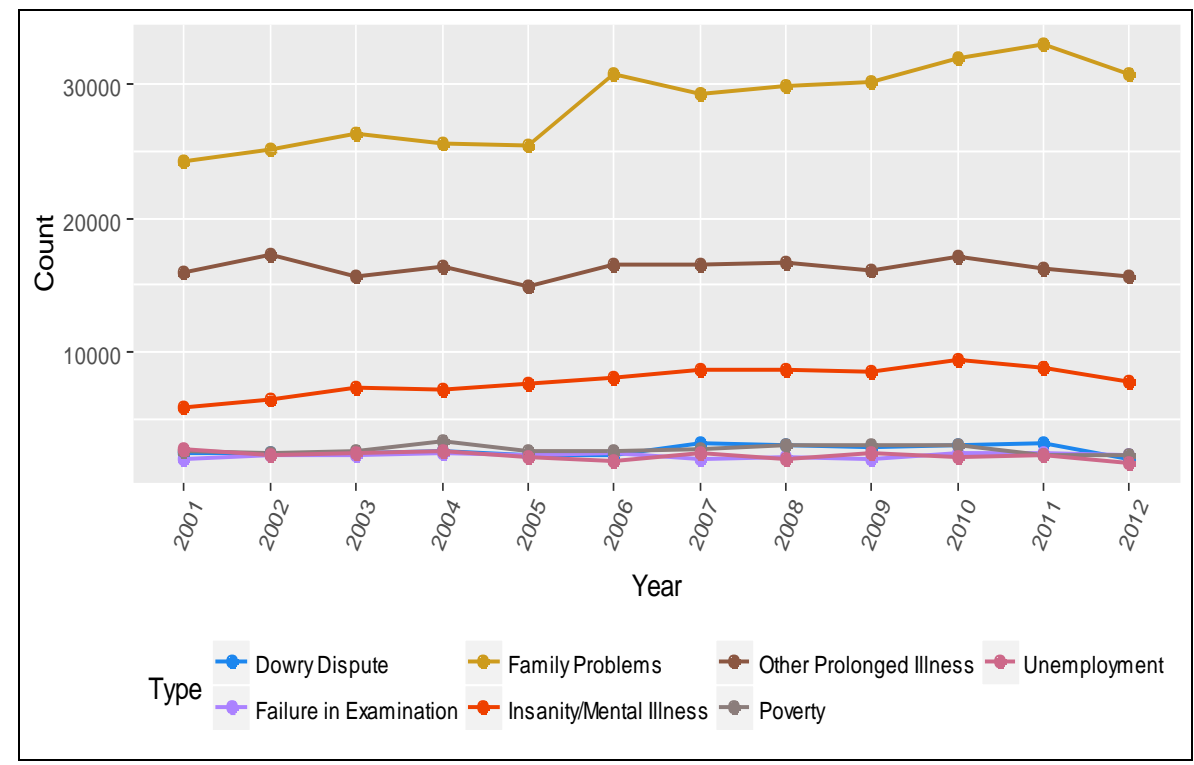

Figure 17. Major Causes for Committing Suicides Year Wise (2001-2012)

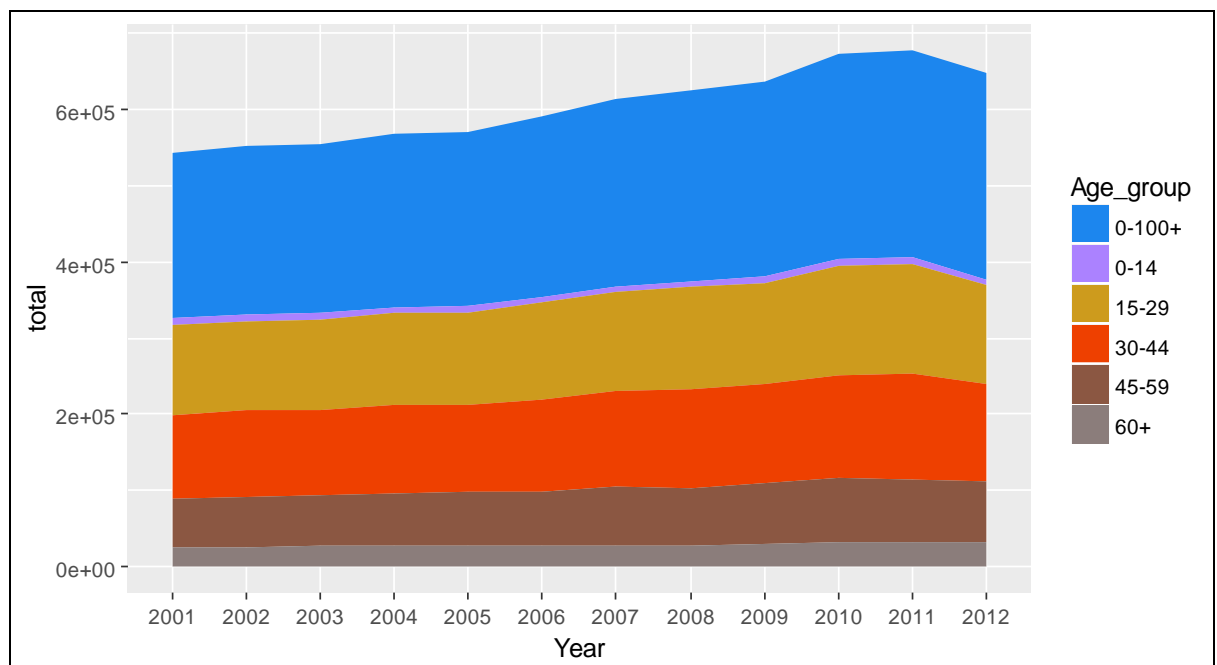

Figure 18. Total Number of Suicides Year Wise (2001-2012) based on Age Group 


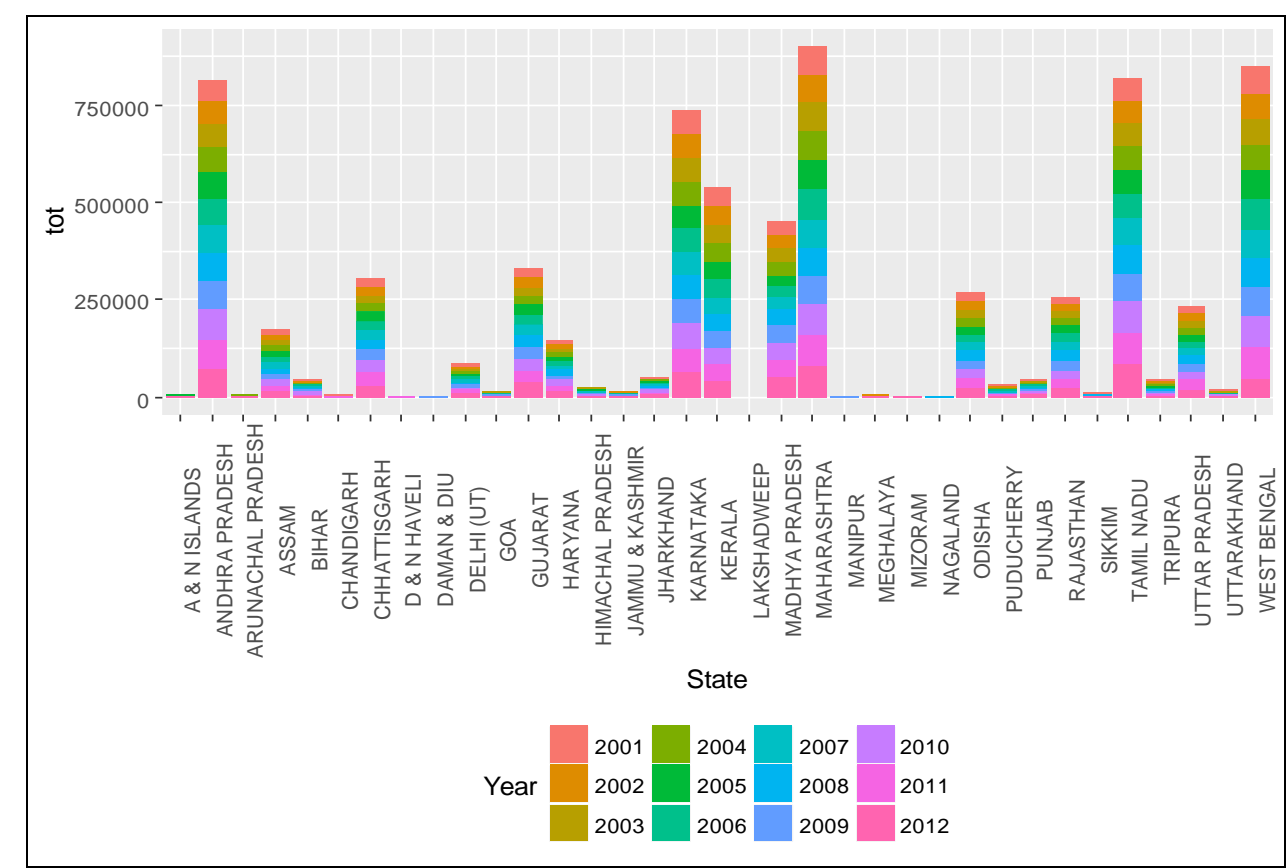

Figure 19. State Wise Total Number of Suicides Year Wise (2001-2012)

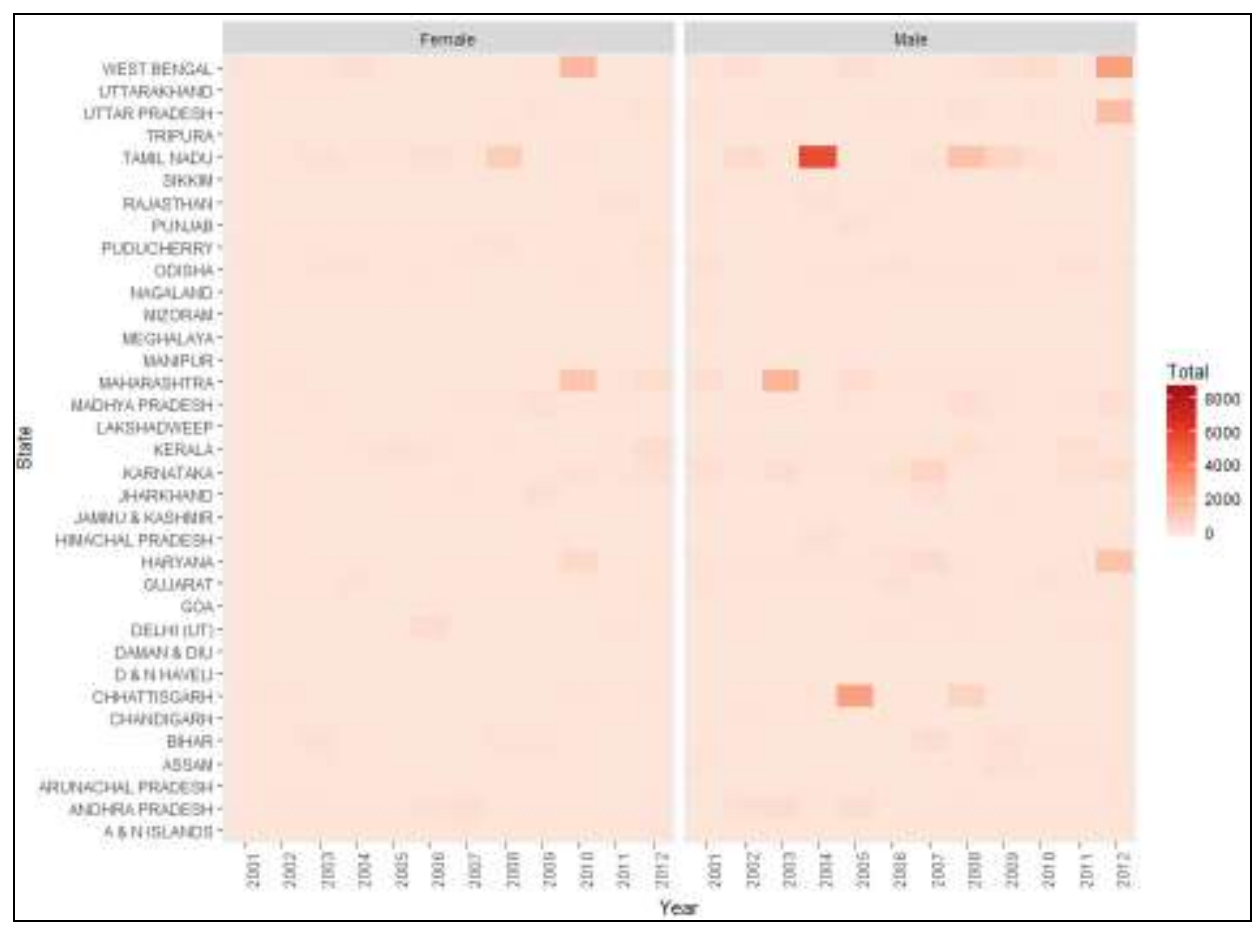

Figure 20. State Wise Top 10 and Bottom 10 Total Number of Suicides Year Wise (2001-2012) 


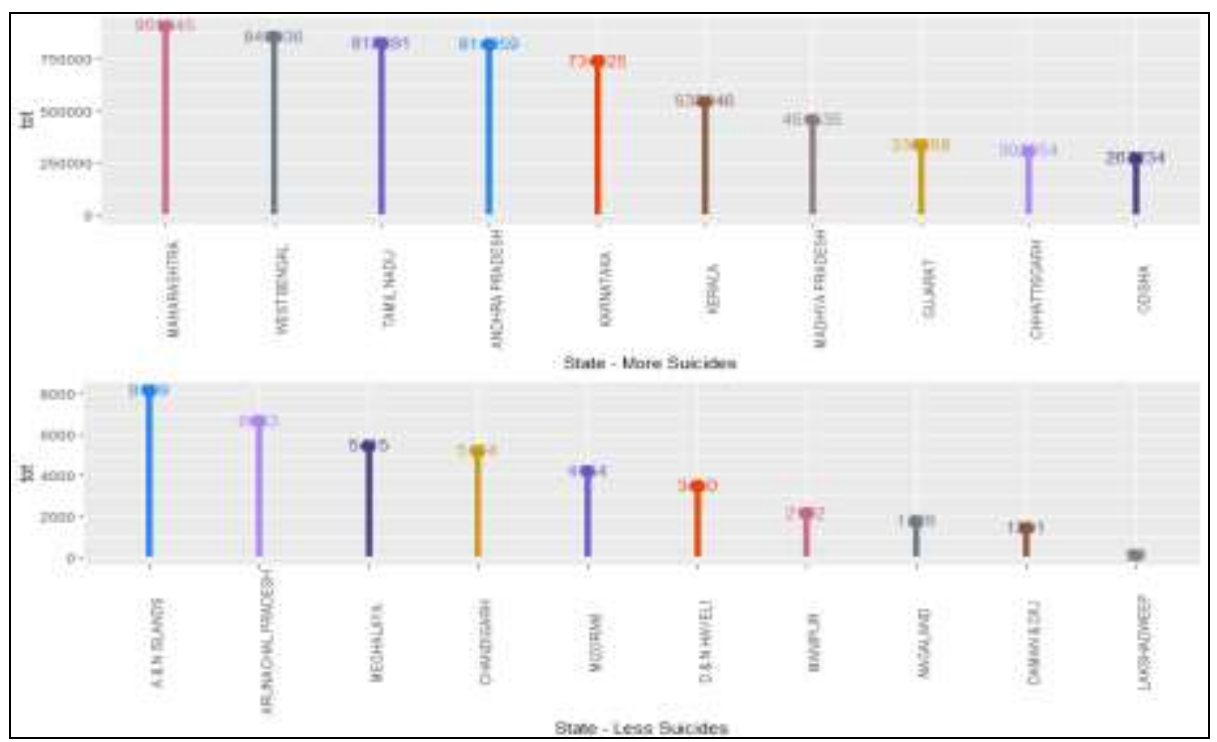

Figure 21. State Wise Top 10 and Bottom 10 Total Number of Suicides

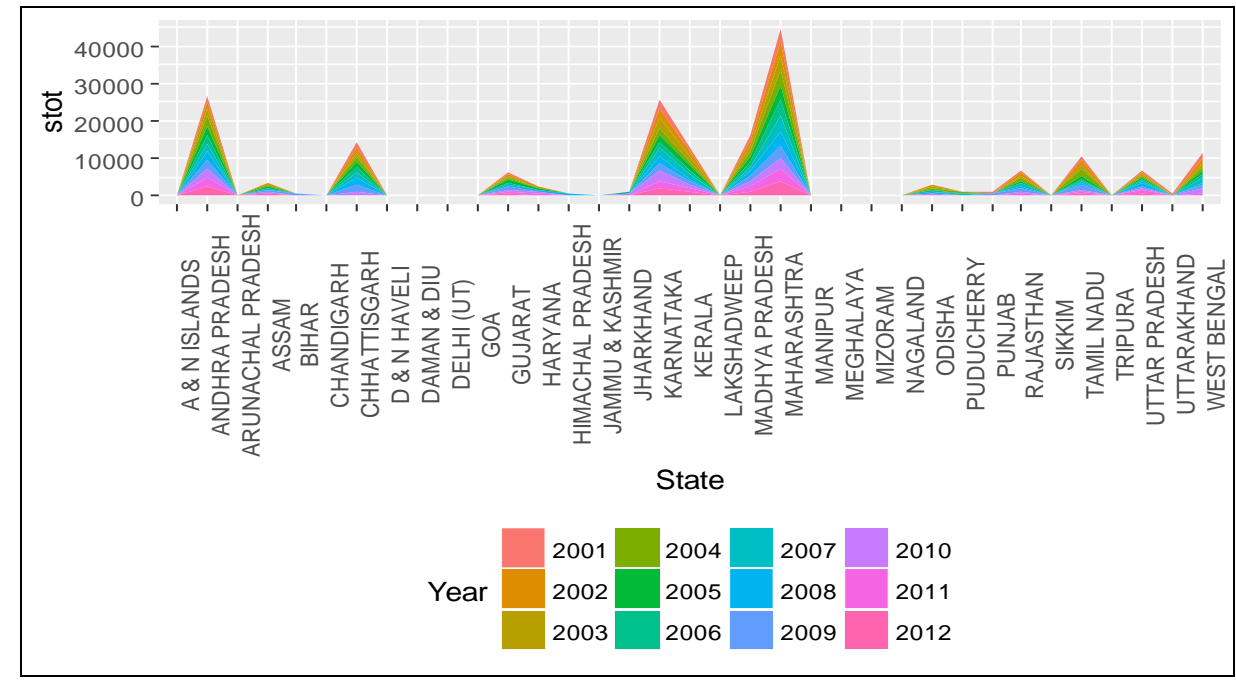

Figure 22. State Wise and Year Wise Total Number of Suicides

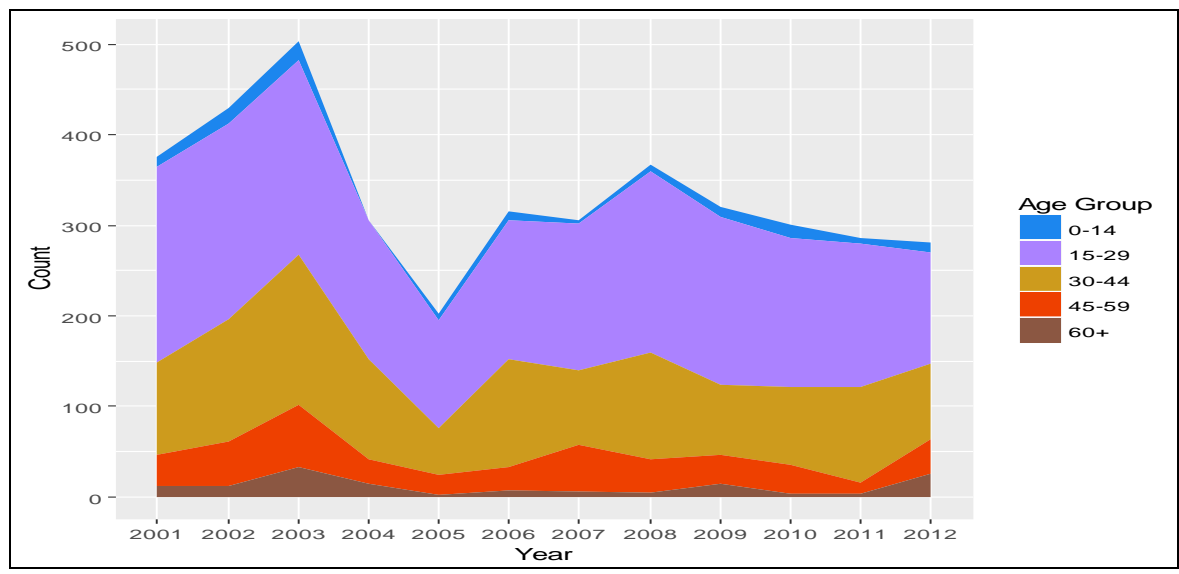

Figure 23. Total Number of Suicides Year Wise based on Age Group 
In the way to find the top 10 and bottom 10 states in India based on the number of suicides, the Figure 20 gives as the complete details of the same. Whereas, in Figure 21 states with more number of suicide cases and less number of suicide cases are plotted.

\section{Conclusion}

In our research, we found that there is a need to do much research on ways of controlling suicide by continuously improving the conceptualization of suicides thoughts and behaviors and by improvising etiological understanding of a individual problem. The students with age group 16-24 are committing suicides as their performance in academics is not that good. In addressing this problem parents needs to improve the level of skill in accepting a challenge and make them learn how to grow along with the problem. The other side, the farmers at the age group 29-45 are also committing suicide due to their commitments made with the family. The facilities provided by the government of India towards irrigation needs to be outlet successfully. In future, with this understanding on suicides, we would like to work on applying machine learning algorithms in evaluating the impact factor of each risk factor and correlation exists among them. This will help in providing the recommendation both to the farmer and the students at different levels of their life.

\section{Acknowledgement}

We sincerely thank to our Executive Director Dr. P. Narasimha Reddy, HoD of IT Dr. V. V. S. S. S. Balaram and Supervisor Dr. N. Ch. S. N. Iyengar for their support and encouragement.

\section{References}

[1] S. Muzamil Basha, Y. Zhenning, D. Singh Rajput, N. Iyengar and R. Caytiles, "Weighted Fuzzy Rule Based Sentiment Prediction Analysis on Tweets", International Journal of Grid and Distributed Computing, vol. 10, no. 6, (2017), pp. 41-54, DOI: 10.14257/ijgdc.2017.10.6.04.

[2] S. Muzamil Basha, Y. Zhenning, D. Singh Rajput, R. D. Caytiles and N. Ch SN Iyengar, "Comparative Study on Performance Analysis of Time Series Predictive Models", International Journal of Grid and Distributed Computing, vol. 10, no. 8, (2017), pp. 37-48, DOI: 10.14257/ijgdc.2017.10.8.04.

[3] S. Muzamil Basha, H. Balaji, N. Ch SN Iyengar and R. D. Caytiles, "A Soft Computing Approach to Provide Recommendation on PIMA Diabetes", International Journal of Advanced Science and Technology, vol. 106, (2017), pp. 19-32, DOI: 10.14257/ijast.2017.106.03.

[4] S. Muzamil Basha, D. Singh Rajput and V. Vandhan, "Impact of Gradient Ascent and Boosting Algorithm in Classification", International Journal of Intelligent Engineering and Systems (IJIES), vol. 11, no. 1, (2018), pp. 41-49, DOI: 10.22266/ijies2018.0228.05.

[5] S. Muzamil Basha, D. Singh Rajput, N. Iyengar and R. Caytiles, "A Novel Approach to Perform Analysis and Prediction on Breast Cancer Dataset using R.”, International Journal of Grid and Distributed Computing, vol. 11, no. 2, (2018), pp. 41-54, http://dx.doi.org/10.14257/ijgdc.2018.11.2.05.

[6] V. P. Khadse, S. Muzamil Basha, N. Iyengar and R. Caytiles, "Recommendation Engine for Predicting Best Rated Movies", International Journal of Advanced Science and Technology, vol. 110, (2018), pp. 65-76, http://dx.doi.org/10.14257/ijast.2018.110.07.

[7] S. Dutta, S. Muzamil Basha, N. Iyengar and R. Caytiles, "Classification of Diabetic Retinopathy Images by Using DeepLearning Models", International Journal of Grid and Distributed Computing, vol. 11, no. 1, (2018), pp. 89-106, http://dx.doi.org/10.14257/ijgdc.2018.11.1.09.

[8] D. Khaturia, S. Muzamil Basha, N. Iyengar and R. Caytiles, "A Comparative study on Airline Recommendation System Using Sentimental Analysis on Customer Tweets", International Journal of Advanced Science and Technology, vol. 111, (2018), pp. 107-114, http://dx.doi.org/10.14257/ijast.2018.111.10.

[9] L. Vijayakumar and S. Rajkumar, "Are risk factors for suicide universal? A case-control study in India", Acta psychiatrica scandinavica, vol. 99, no. 6, (1999) June 1, pp. 407-11.

[10] T. A. Carleton, "Crop-damaging temperatures increase suicide rates in India", Proceedings of the National Academy of Sciences, (2017) July 31:201701354.

[11] T. Thomas, "Prevention of Inpatient Suicides: An Attempt to Portray an Approach", Kerala Journal of Psychiatry, vol. 30, no. 2, (2017). 
[12] C. B. Cha, P. J. Franz, E. M Guzmán, C. R. Glenn, E. M. Kleiman and M. K. Nock, "Annual Research Review: Suicide among youth-epidemiology", (potential) etiology, and treatment. Journal of child psychology and psychiatry, (2017) November 1.

[13] M. A. Just, L. Pan, V. L. Cherkassky, D. L. McMakin, C. Cha, M. K. Nock and D. Brent, "Machine learning of neural representations of suicide and emotion concepts identifies suicidal youth", Nature Human Behaviour, vol. 12, vol. 911, (2017) December 1.

[14] D. Swami, P. Dave and D. Parthasarathy, "Agricultural susceptibility to monsoon variability: A district level analysis of Maharashtra, India", Science of The Total Environment, vol. 619, (2018) April 1, pp. 559-77.

[15] W. Kyung-Sook, S. SangSoo, S. Sangjin and S. Young-Jeon, "Marital status integration and suicide: a meta-analysis and meta-regression", Social Science \& Medicine, vol. 197, (2018) January 31, pp. 11626.

[16] S. R. D'sa, S. Nair, V. Joe Philip, K. K. Reji, R. Karuppusamy and M. Joseph, "Study of the factors at admission predicting the outcome in patients with attempted suicidal hanging", Tropical doctor, vol. 48, no. 1, (2018) January, pp. 3-6.

\section{Authors}

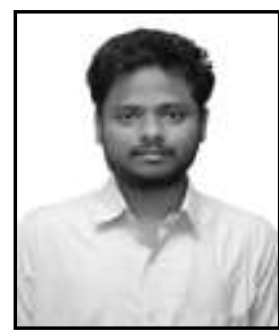

K. Sai Teja, currently pursuing B. Tech in Information Technology from Department of Information Technology, Sreenidhi Institute of Science and Technology, Yamnampet, Ghatkesar, Hyderabad, Telangana 501301. His research interests include Machine Learning, Cloud computing and Big Data.

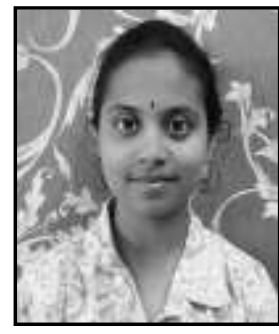

S. Pravalika, currently pursuing B. Tech in Information Technology from Department of Information Technology, Sreenidhi Institute of Science and Technology, Yamnampet, Ghatkesar, Hyderabad, Telangana 501301. His research interests include Artificial Intelligence, Cloud computing and Big Data.

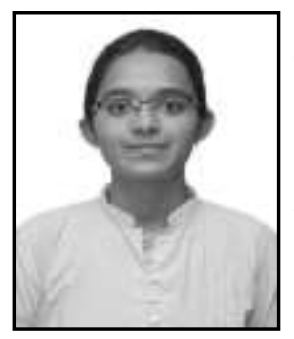

G. Varshitha, currently pursuing B. Tech in Information Technology from Department of Information Technology, Sreenidhi Institute of Science and Technology, Yamnampet, Ghatkesar, Hyderabad, Telangana 501301. His research interests include Artificial Intelligence, Cloud computing and Big Data.

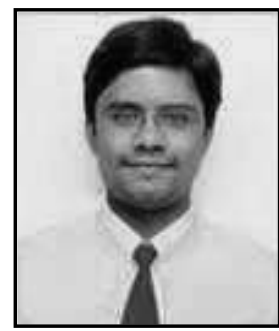

Syed Muzamil Basha, he had his Bachelor of Science in Information Technology at SITAMS, MTech in Information Technology (Networking) at VIT University and currently working as Assistant professor in the department of Information Technology at SVCET, Chittoor. His research area are Wireless Sensor Networks, Text Mining and Big Data Predictive Analytics. 


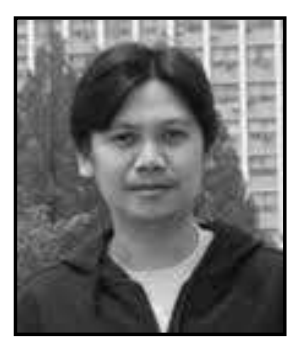

Ronnie D. Caytiles, he had his Bachelor of Science in Computer Engineering- Western Institute of Technology, Iloilo City, Philippines, and Master of Science in Computer Science- Central Philippine University, Iloilo City, Philippines. He finished his Ph.D. in Multimedia Engineering, Hannam University, Daejeon, Korea. Currently, he serves as an Assistant Professor at Multimedia Engineering department, Hannam University, Daejeon, Korea. His research interests include Mobile Computing, Multimedia Communication, Information Technology Security, Ubiquitous Computing, Control and Automation.

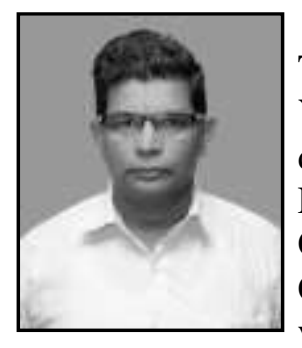

N. Ch. S. N. Iyengar (b 1961), currently Professor, Information Technology, Sreenidhi Institute of Science (SNIST) and Technology, Yamnapet, Ghatkesr, Hyderabad-501301, Telengana, India $\mathrm{He}$ is a doctorate in both Applied Mathematics and Computer Science and Engineering. His research interests include Agent-Based Distributed Computing, Intelligent Computing, Network Security, Cloud Computing, Big Data Analytics and Fluid Mechanics. He had 32+ years of experience in teaching to B.Tech. and M.Tech students. He guided 12 Ph.Ds ,5 M.Phils and $75+$ M.Tech Projects apart from authoring several textbooks. He had $220+$ research publications in reputed peer reviewed international journals along with students. He organized many conferences/workshops and continuing education programmes. He served as Keynote speaker/ / Invited speaker //PCM/reviewer for many International conferences. He serves as a Editor in chief/Guest editor /Editorial board member for many international journals. He is the professional member of many bodies. 